\title{
RVCL-S and CADASIL display distinct impaired vascular function
}

Irene de Boer, MD,* Anine H. Stam, MD, PhD, * Linde Buntinx, MSc, Ronald Zielman, MD, Iris van der Steen, MD, Arn M.J.M. van den Maagdenberg, PhD, Eelco J.P. de Koning, MD, PhD, Michel D. Ferrari, MD, PhD, Jan N. de Hoon, MD, PhD,* and Gisela M. Terwindt, MD, PhD*

Neurology ${ }^{\circledR}$ 2018;91:e956-e963. doi:10.1212/WNL.0000000000006119

\section{Abstract}

\section{Objective}

We aimed to evaluate the role of endothelial-dependent and endothelial-independent vascular reactivity in retinal vasculopathy with cerebral leukoencephalopathy and systemic manifestations (RVCL-S) and cerebral autosomal dominant arteriopathy with subcortical infarcts and leukoencephalopathy (CADASIL), both cerebral small vessel diseases are considered models for stroke, vascular dementia, and migraine.

\section{Methods}

RVCL-S $(\mathrm{n}=18)$ and CADASIL $(\mathrm{n}=23)$ participants with TREX1 and NOTCH3 mutations, respectively, were compared with controls matched for age, body mass index, and sex $(n=26)$. Endothelial function was evaluated by flow-mediated vasodilatation, and endothelial-independent vascular reactivity (i.e., vascular smooth muscle cell function) was assessed by dermal blood flow response to capsaicin application.

\section{Results}

Flow-mediated vasodilatation was decreased in participants with RVCL-S compared with controls $(2.32 \% \pm 3.83 \%$ vs $5.76 \% \pm 3.07 \%$ change in diameter, $p=0.023)$ but normal in participants with CADASIL. Vascular smooth muscle cell function was reduced in participants with CADASIL compared with controls (maximal dermal blood flow increase at 40 minutes after capsaicin: $1.38 \pm 0.88$ vs $2.22 \pm 1.20$ arbitrary units, $p=0.010$ ) but normal in participants with RVCL-S.

\section{Conclusions}

We identified endothelial dysfunction in RVCL-S and confirmed impaired vascular smooth muscle cell relaxation in CADASIL. Our findings may prove to be biomarkers for disease progression in both monogenic cerebral small vessel diseases and improve mechanistic insight in their pathophysiology. This may help in understanding common neurovascular disorders, including stroke, dementia, and migraine.

*These authors contributed equally to this work.

From the Departments of Neurology (I.d.B., A.H.S., R.Z., I.v.d.S., A.M.J.M.v.d.M., M.D.F., G.M.T.), Human Genetics (A.M.J.M.v.d.M.), and Internal Medicine (E.J.P.d.K.), Leiden University Medical Center, Leiden, the Netherlands; and Center for Clinical Pharmacology (L.B., J.N.d.H.), University Hospitals Leuven and Department of Pharmaceutical and Pharmacological Sciences, KU Leuven, Belgium.

Go to Neurology.org/N for full disclosures. Funding information and disclosures deemed relevant by the authors, if any, are provided at the end of the article. 


\section{Glossary}

AU = arbitrary unit; AUC = area under the curve; $\mathbf{B M I}=$ body mass index; CADASIL $=$ cerebral autosomal dominant arteriopathy with subcortical infarcts and leukoencephalopathy; CGRP = calcitonin gene-related peptide; DBF = dermal blood flow; FMD = flow-mediated dilatation; NTG = nitroglycerin; RVCL-S = retinal vasculopathy with cerebral leukoencephalopathy and systemic manifestations; TRPV1 = transient receptor potential vanilloid type 1; VSMC = vascular smooth muscle cell.

Retinal vasculopathy with cerebral leukoencephalopathy and systemic manifestations (RVCL-S) and cerebral autosomal dominant arteriopathy with subcortical infarcts and leukoencephalopathy (CADASIL) are monogenic small vessel diseases with overlapping clinical features, including white matter lesions and stroke. Migraine and depressive symptoms are often presenting symptoms, and in many patients, apathy and premature cognitive decline are found. ${ }^{1-7}$ Because of clinical similarities, these monogenic syndromes may serve as a model for common vascular disorders, including stroke, vascular dementia, and migraine.

In CADASIL, degeneration of vascular smooth muscle cells (VSMCs) with morphologically normal endothelium is observed. ${ }^{5}$ In contrast, in RVCL-S, muscle cell degeneration is minimal, but electron microscopy shows irregular thickening of basement membranes, whose formation is dependent on endothelial cells. ${ }^{7,8}$ These morphologic abnormalities supposedly affect the dilatation capability of blood vessels, which may lead to hypoxia. Studies in CADASIL showed reduced baseline cerebral blood flow and impaired hemodynamic reserve with an impaired vasodilation response to acetazolamide. ${ }^{9-11}$ However, it is unclear whether this reduced vascular reactivity is caused by an endothelium-independent or -dependent mechanism. ${ }^{12-16}$ In RVCL-S, functional vascular properties have not been studied. Furthermore, in RVCL-S, there is systemic involvement of highly vascularized organs, and in CADASIL, involvement of peripheral blood vessels has been demonstrated by electron microscopy and staining of NOTCH3 ${ }^{1,5}$ Therefore, we investigated whether participants with RVCL-S or CADASIL have impaired vascular reactivity and whether this is mediated by endothelial dysfunction or by a VSMC-mediated mechanism in the peripheral blood vessels.

\section{Methods}

\section{Standard protocol approvals, registrations, and patient consents}

The study was approved by the ethics committee of the Leiden University Medical Center and conducted in accordance with the Declaration of Helsinki. All participants were at least 18 years of age and gave written informed consent.

\section{Participants}

Participants with RVCL-S or CADASIL who had a confirmed pathogenic gene mutation in TREX1 or NOTCH3, respectively, were recruited. Controls were recruited through the families (friends or spouses, not related individuals) and public advertisements. An investigator, different from the operator performing the vascular measurements, obtained medical history and genetic and clinical information. To prevent unblinding, participants were instructed not to reveal their mutation status or medical history to the operator. Patients were matched to controls by age, body mass index (BMI), and sex.

\section{Clinical assessment}

Participants completed a questionnaire with variables on medical history including migraine, Raynaud phenomenon, retinopathy, and other medical conditions. Additional questions related to current medication, alcohol, caffeine, smoking, and drug intake were asked. During the interview preceding the measurements, diagnoses of migraine and Raynaud phenomenon were verified, according to established criteria. ${ }^{17,18}$ Medication was subdivided in the following categories: antihypertensive, cholesterollowering, antiplatelet, anticoagulant, prophylactic migraine medication, analgesics, and oral contraceptive. If possible, participants included in the study were asked to abstain from medication with vascular (side) effects for 1 week before the measurements. Participants were instructed to abstain from alcohol and caffeine (for 12 hours) and smoking and food (for 6 hours). This was verified during the interview. Weight and height were measured, and BMI was calculated.

\section{Biochemical measurements}

Laboratory measures (table 1) were determined according to standard procedures.

\section{Experimental design}

One operator, blinded to the participants' status, performed all vascular measurements. Before the vascular measurements, participants rested in supine position for 15 minutes in a room with recorded stable ambient temperature $\left(22^{\circ} \mathrm{C} \pm 1^{\circ} \mathrm{C}\right)$. Resting blood pressure and pulse rate were recorded at the right upper arm using a validated semiautomated oscillometric device (OMRON 705IT; OMRON Healthcare, Hoofddorp, the Netherlands). Median blood pressure and heart rate of 3 measurements were analyzed. Subsequently, flow-mediated dilatation (FMD) and capsaicin-induced dermal blood flow (DBF) were measured in a standardized order.

\section{FMD (endothelial function of conduit artery)}

FMD of the brachial artery was performed to assess endothelium-dependent vasodilatation according to guidelines ${ }^{19}$ using an echo-tracking system (Wall Track System; Pie Medical, Maastricht, the Netherlands). The system consists of an 
Table 1 Participants' demographics

\begin{tabular}{|c|c|c|c|c|}
\hline Variable & Controls $(n=26)$ & CADASIL $(n=23)$ & RVCL-S $(n=18)$ & $p$ Value \\
\hline Age, y & $49.0 \pm 9.1$ & $49.5 \pm 12.7$ & $50.1 \pm 9.6$ & $0.94^{\mathrm{g}}$ \\
\hline $\mathrm{BMI}, \mathrm{kg} / \mathrm{m}^{2}$ & $25.2 \pm 3.6$ & $26.7 \pm 4.3$ & $25.2 \pm 3.7$ & $0.17^{\mathrm{h}}$ \\
\hline Systolic blood pressure, $\mathrm{mm} \mathrm{Hg}$ & $129.2 \pm 20.5$ & $126.2 \pm 11.1$ & $132.8 \pm 21.7$ & $0.85^{\mathrm{h}}$ \\
\hline Diastolic blood pressure, $\mathrm{mm} \mathrm{Hg}$ & $77.8 \pm 10.1$ & $75.4 \pm 6.7$ & $75.3 \pm 8.8$ & $0.41^{\mathrm{h}}$ \\
\hline Female & $14(54)$ & $11(48)$ & $10(56)$ & $0.87^{i}$ \\
\hline Smoking, pack-y & $3.0 \pm 5.0^{\mathrm{a}}$ & $13.4 \pm 16.0$ & $3.7 \pm 5.8$ & $0.029^{h}$ \\
\hline Migraine & $0(0)$ & $6(27)^{b}$ & $6(33)$ & NA \\
\hline Retinopathy & $0(0)$ & $0(0)$ & $9(56)^{c}$ & NA \\
\hline Raynaud phenomenon & $0(0)$ & $3(13)$ & $15(83)$ & \\
\hline Chronic medication use $^{d}$ & $5(19)$ & $17(74)$ & $12(67)$ & NA \\
\hline Oral contraceptive use (\% of women) & $3(21)$ & $1(9)$ & $0(0)$ & \\
\hline Antihypertensive drugs & $0(0)$ & $6(26)[1]$ & $6(33)[2]$ & \\
\hline Cholesterol-lowering medication & $0(0)$ & 9 (39) [2] & $6(33)[2]$ & \\
\hline Antiplatelet drugs & $0(0)$ & $13(57)[3]$ & $8(44)[4]$ & \\
\hline Prophylactic migraine medication & $0(0)$ & $1(4)$ & $0(0)$ & \\
\hline Analgesics (acetaminophen, NSAIDs) & $1(4)$ & $2(9)$ & $5(28)$ & \\
\hline Other $(\%)^{f}$ & $1(4)[1]$ & $7(30)[1]$ & $10(56)[3]$ & \\
\hline \multicolumn{5}{|l|}{ Laboratory parameters } \\
\hline $\mathrm{Hb}, \mathrm{g} / \mathrm{dL}$ & $8.99 \pm 0.71$ & $9.15 \pm 0.73$ & $8.10 \pm 0.65$ & $<0.001^{\mathrm{g}}$ \\
\hline $\mathrm{Ht}, \%$ & $0.43 \pm 0.03$ & $0.44 \pm 0.04$ & $0.40 \pm 0.04$ & $0.001^{g}$ \\
\hline
\end{tabular}

Abbreviations: $\mathrm{BMI}=$ body mass index; $\mathrm{CADASIL}=$ cerebral autosomal dominant arteriopathy with subcortical infarcts and leukoencephalopathy; $\mathrm{Hb}=$ hemoglobin; $\mathrm{Ht}$ = hematocrit; NA = not applicable; NSAID = nonsteroidal anti-inflammatory drug; RVCL-S = retinal vasculopathy with cerebral leukoencephalopathy and systemic manifestations.

Values are presented as mean \pm SD or $n(\%)$.

a For one participant, pack-years was unavailable.

${ }^{\mathrm{b}}$ For one participant, migraine was unclear.

c Retinopathy status for 2 participants unknown.

${ }^{\mathrm{d}}$ Number of participants who abstained from medication 7 days before the measurements are depicted in square brackets. No participant used oral anticoagulants.

e All participants used these painkillers for acute migraine treatment; none used acetaminophen or NSAIDs 24 hours before measurements.

f Other medication: glucose-lowering drugs, stomach acid inhibitors, alfuzosin, solifenacin, gabapentin, carbamazepine, pyridoxine, folic acid, valproic acid, alfacalcidol, allopurinol, dorzolamide/timolol and dexamethasone eye drops, baclofen, antihistamine drugs, ursodeoxycholic acid, lynestrenol, levothyroxine, atovaquone, darbepoetin alfa.

$\mathrm{g}$ One-way analysis of variance.

${ }^{\mathrm{h}}$ Kruskal-Wallis test.

'Chi-square test.

ultrasound device (Esaote AU5; Esaote Biomedical, Genoa, Italy) connected to a data acquisition and processing unit. Measurements were performed as described earlier. ${ }^{20}$ In brief, right brachial artery diameter was measured 5 to $10 \mathrm{~cm}$ proximal to the antecubital crease in a longitudinal plane. At baseline, brachial artery diameter and arterial blood velocity profiles were recorded 3 times; the mean was used for data analysis. After baseline measurements, a cuff (TMC7; D.E. Hokanson, Bellevue, WA), placed around the forearm, was inflated to $220 \mathrm{~mm} \mathrm{Hg}$ to temporarily occlude the arterial perfusion. The cuff was released after 5 minutes with recording of the peak blood velocity profile within the first 15 seconds. Brachial artery diameter was measured for 4 seconds at $0.5,0.75,1,1.25,1.5$, and $2-5$ minutes after cuff release. FMD was expressed as maximal absolute and percentage increase in diameter from baseline. The FMD was corrected for hyperemic stimulus using peak shear rate (peak flow velocity/ baseline diameter) and for blood viscosity using peak shear stress (peak shear rate $x$ hematocrit) by dividing the FMD by the peak shear rate and shear stress, respectively.

After 15 minutes of recovery, $400 \mu \mathrm{g}$ of sublingual nitroglycerin (NTG) was administered as an exogenous nitric oxide donor, and every minute for 6 minutes NTG-induced brachial 
artery dilatation was assessed. Endothelium-independent vasodilatation capacity after administration of NTG was expressed as percentage increase in diameter from baseline. After 1 week, we asked participants whether a migraine attack was provoked by NTG.

\section{Capsaicin-induced DBF (microcirculation in the skin)}

Local application of capsaicin results in binding to the transient receptor potential vanilloid type 1 (TRPV1) receptor, which is present at primary sensory neurons (A $\delta$ - and $\mathrm{C}$-fiber nociceptors). TRPV1 receptor binding of capsaicin induces a neurogenic inflammatory response caused by predominant release of calcitonin gene-related peptide (CGRP). ${ }^{21}$ CGRP is a very potent vasodilator causing a local increase in $\mathrm{DBF}$, which can be quantified by laser Doppler perfusion imaging (PeriScan PIM II; Perimed, Järfälla, Sweden). Reproducibility of this test was confirmed earlier. ${ }^{22}$ After 20 minutes of supine rest, the baseline DBF was measured. Participants received single topical doses of $1,000 \mu \mathrm{g}$ per $20 \mu \mathrm{L}$ of capsaicin (in ethanol/polysorbate 20/ water) in two 10-mm rubber O-rings on the volar surface of one forearm. In 2 rings on the opposite arm, vehicle was applied; DBF was measured at 10, 20,30, and 40 minutes after capsaicin application. Almost half of the CADASIL group was measured on a differently calibrated laser Doppler perfusion imaging scanner, for which a separate control group was recruited. Results are expressed as arbitrary units (AU) presented as change vs baseline in DBF after capsaicin application.

\section{Statistical analysis}

Continuous variables are presented as mean \pm SD and discrete variables as counts (percentages) unless indicated otherwise. The Shapiro-Wilk test was used to determine whether the data were normally distributed. General characteristics of each group were compared using a 1-way analysis of variance for normally distributed continuous variables (Kruskal-Wallis test for nonnormally distributed variables) and the $\chi^{2}$ test for categorical variables. The results from the FMD were compared using the independent sample $t$ test for normally distributed variables and the Mann-Whitney $U$ test for nonnormally distributed variables. Mean increase in DBF after capsaicin (40 minutes) and mean area under the curve over 40 minutes $\left(\mathrm{AUC}_{0-40}\right)$ were compared using the 1-way analysis of covariance to take into account the use of 2 scanners. For all analyses, a 2-sided $p$ value of $\alpha<0.05$ was considered statistically significant. All statistical analyses were performed using SPSS 23.0 software (IBM Corp., Armonk, NY).

\section{Data availability}

Anonymized data not published within this article will be made available by request from any qualified investigator.

\section{Results}

\section{Participants}

Eighteen participants with RVCL-S and 23 with CADASIL were compared with 26 matched controls. In table 1, demographic details, clinical symptoms, and laboratory values are summarized. All tests were well tolerated. No participant reported an NTG-provoked migraine attack. Abstaining from alcohol, caffeine, smoking, and food was successful, except for smoking in the CADASIL group (78\% abstinence; 5 participants smoked $<6$ hours before measurements), abstinence from alcohol in the RVCL-S group (94\% abstinence; one participant used 2 units of alcohol $<10$ hours before measurements), and caffeine in the CADASIL group ( $96 \%$ abstinence; one participant used 1 unit of coffee $<6$ hours before measurements). Success for abstaining from medication is depicted in table 1 . Not all participants could be included for all measurements. No significant differences for age, sex, BMI, and blood pressure were found between included participants and those excluded.

\section{Flow-mediated dilatation}

FMD was performed in 18 participants with RVCL-S, 14 with CADASIL, and 18 controls, but a valid set could only be obtained in 10 participants of each disease group and in 14 controls. When a valid set could not be obtained, this was attributed to technical difficulties with ECG gating (6) and movement artifacts (10). Participants with RVCL$\mathrm{S}$ showed a lower FMD compared with controls (2.32 \pm 3.83 vs $5.76 \pm 3.07, p=0.023$ ) (figure 1 ). No significant difference in FMD was observed between participants with CADASIL and controls $(3.77 \pm 3.15$ vs $5.76 \pm$ 3.07, $p=0.14)$. The decreased FMD in RVCL-S persisted after correction for peak shear rate $(p=0.015)$ and peak shear stress $(p=0.027)($ table 2$)$. There was no difference between participants with RVCL-S and CADASIL and controls in FMD after the admission of NTG (table 2).

Figure 1 Flow-mediated dilatation expressed as the percentage change in brachial artery diameter after hyperemic stimulus in participants with RVCL-S, participants with CADASIL, and controls

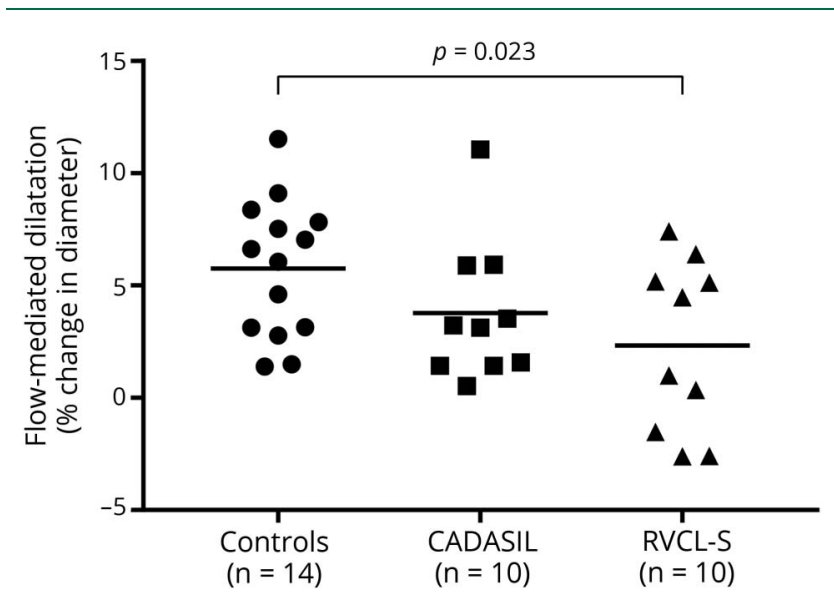

CADASIL = cerebral autosomal dominant arteriopathy with subcortical infarcts and leukoencephalopathy; RVCL-S = retinal vasculopathy with cerebral leukoencephalopathy and systemic manifestations. 
Table 2 Vascular parameters of the brachial artery

\begin{tabular}{|c|c|c|c|c|c|}
\hline Variable & Controls $(n=14)$ & CADASIL $(n=10)$ & $p$ Value $^{a}$ & RVCL-S $(n=10)$ & $p$ Value $^{\mathrm{b}}$ \\
\hline Preocclusion diameter, $\mu \mathrm{m}$ & $5,655 \pm 1,014$ & $5,934 \pm 839$ & $0.48^{c}$ & $6,438 \pm 1,103$ & $0.09^{c}$ \\
\hline Maximal postocclusion diameter, $\mu \mathrm{m}$ & $5,987 \pm 1,109$ & $6,150 \pm 828$ & $0.70^{c}$ & $6,602 \pm 1,252$ & $0.22^{c}$ \\
\hline FMD (absolute increase in diameter), $\mu \mathrm{m}$ & $332 \pm 187$ & $216 \pm 169$ & $0.13^{c}$ & $165 \pm 256$ & $0.08^{c}$ \\
\hline Preocclusion velocity, $\mathrm{cm} / \mathrm{s}$ & $11.7 \pm 4.1$ & $9.5 \pm 3.4$ & $0.20^{d}$ & $13.4 \pm 6.3$ & $0.76^{\mathrm{d}}$ \\
\hline Maximal postocclusion velocity, $\mathrm{cm} / \mathrm{s}$ & $82.4 \pm 24.9$ & $81.7 \pm 20.5$ & $0.94^{c}$ & $88.5 \pm 21.4$ & $0.56^{c}$ \\
\hline Peak shear rate, $\mathbf{s}^{-1}$ & $140.6 \pm 33.7$ & $138.4 \pm 35.7$ & $1.00^{d}$ & $141.4 \pm 34.6$ & $0.94^{d}$ \\
\hline Peak shear rate normalized FMD $\left(\times 10^{-3}\right), \% \times s$ & $4.35 \pm 2.31$ & $2.99 \pm 2.33$ & $0.20^{c}$ & $1.32 \pm 2.91$ & $0.015^{c}$ \\
\hline Peak shear stress, $\mathrm{s}^{-1}$ & $61.6 \pm 16.2$ & $59.6 \pm 14.6$ & $0.78^{c}$ & $56.3 \pm 15.3$ & $0.46^{\mathrm{c}}$ \\
\hline Peak shear stress normalized FMD $\left(\times 10^{-3}\right), \% \times s$ & $10.07 \pm 5.73$ & $6.96 \pm 5.58$ & $0.23^{c}$ & $3.31 \pm 7.24$ & $0.027^{c}$ \\
\hline Pre-NTG diameter, $\mu \mathrm{m}$ & $5,710 \pm 844$ & $6,198 \pm 1,019$ & $0.21^{c}$ & $6,190 \pm 1,034$ & $0.22^{c}$ \\
\hline Maximal post-NTG diameter, $\mu \mathrm{m}$ & $6,496 \pm 899$ & $6,947 \pm 891$ & $0.18^{d}$ & $6,980 \pm 1,193$ & $0.29^{d}$ \\
\hline Post-NTG, \% change in diameter & $14.13 \pm 6.71$ & $12.72 \pm 6.61$ & $0.62^{c}$ & $12.99 \pm 7.39$ & $0.70^{c}$ \\
\hline
\end{tabular}

Abbreviations: CADASIL = cerebral autosomal dominant arteriopathy with subcortical infarcts and leukoencephalopathy; FMD = flow-mediated dilatation; NTG = nitroglycerin; RVCL-S = retinal vasculopathy with cerebral leukoencephalopathy and systemic manifestations.

Data are presented as mean \pm SD. Because of missing peak shear rate and stress, the corrected FMD could not be calculated in 2 controls and in one participant of each disease group.

a Difference between controls and participants with CADASIL.

b Difference between controls and participants with RVCL-S.

'Sample $t$ test.

${ }^{\mathrm{d}}$ Mann-Whitney $U$ test.

\section{Capsaicin-induced DBF}

Capsaicin-induced DBF measurements were performed in 18 participants with RVCL-S, 20 participants with CADASIL, and equal numbers of matching controls. Three participants were excluded because of skin allergy to alcohol-containing solutions, colored skin, or prophylactic antimigraine medication (pizotifen). Results are summarized in figure 2. Participants with CADASIL compared with controls displayed a lower increase in DBF 40 minutes after capsaicin application $(1.38 \pm 0.88$ vs $2.22 \pm 1.20 \mathrm{AU}, p=0.010)$ and a lower $\mathrm{AUC}_{0-40}(37.8 \pm 23.0$ vs $57.9 \pm 36.6 \mathrm{AU} \times \min , p=0.043)$. No significant differences were found between participants with RVCL-S and controls.

\section{Discussion}

This study provides evidence for endothelial dysfunction in patients with RVCL-S. In addition, an impaired endothelialindependent vascular reactivity in the microvasculature is confirmed in patients with CADASIL.

RVCL-S is caused by heterozygous C-terminal frameshift mutations in the TREX1 gene, ${ }^{7}$ which encodes the major $3^{\prime}-5^{\prime}$ DNA exonuclease. ${ }^{23}$ How TREX1 mutations exactly lead to RVCL-S remains an enigma. TREX1 mutations that cause RVCL-S preserve the enzymatic function of the protein but alter its intracellular localization because the $\mathrm{C}$-terminus that anchors to the endoplasmic reticulum is absent. RVCL-S mutations are hypothesized to lead to a toxic gain-of-function that primarily affects the microvasculature through a mechanism that remains undetermined. Endothelial dysfunction might be such a mechanism. Mutated TREX1 protein may directly have detrimental effects on endothelial cells and thereby cause further pathologic changes causing clinical symptoms. Alternatively, endothelial dysfunction may be a consequence of the pathologic changes seen in RVCL-S. Regardless, clinical symptoms that occur in patients with RVCL-S, i.e., cerebral infarction, ${ }^{24}$ Raynaud phenomenon, ${ }^{25}$ migraine, ${ }^{20}$ and subcortical cognitive dysfunction (executive function, processing speed) ${ }^{26}$ all have been linked to endothelial dysfunction. It should be noted that we did not measure endothelial function at the level of resistance arteries. Consequently, we are unable to determine whether endothelial dysfunction in RVCL-S can be extrapolated to small resistance vessels, but this seems likely. Iontophoresis or venous occlusion plethysmography with acetylcholine would be of interest as a follow-up study to further explore this. Only minimal degeneration of VSMCs is seen in RVCL-S, which is in accordance with findings of normal VSMC function in RVCL-S in our study.

CADASIL is caused by heterozygous missense mutations (that change the number of cysteine residues) in the NOTCH3 gene, ${ }^{6}$ which encodes a cell surface receptor that is expressed on VSMCs. NOTCH3 is involved in a signal transduction pathway critical for development, homeostasis, and differentiation of VSMCs. ${ }^{27} \mathrm{~A}$ decreased DBF response to capsaicin was 

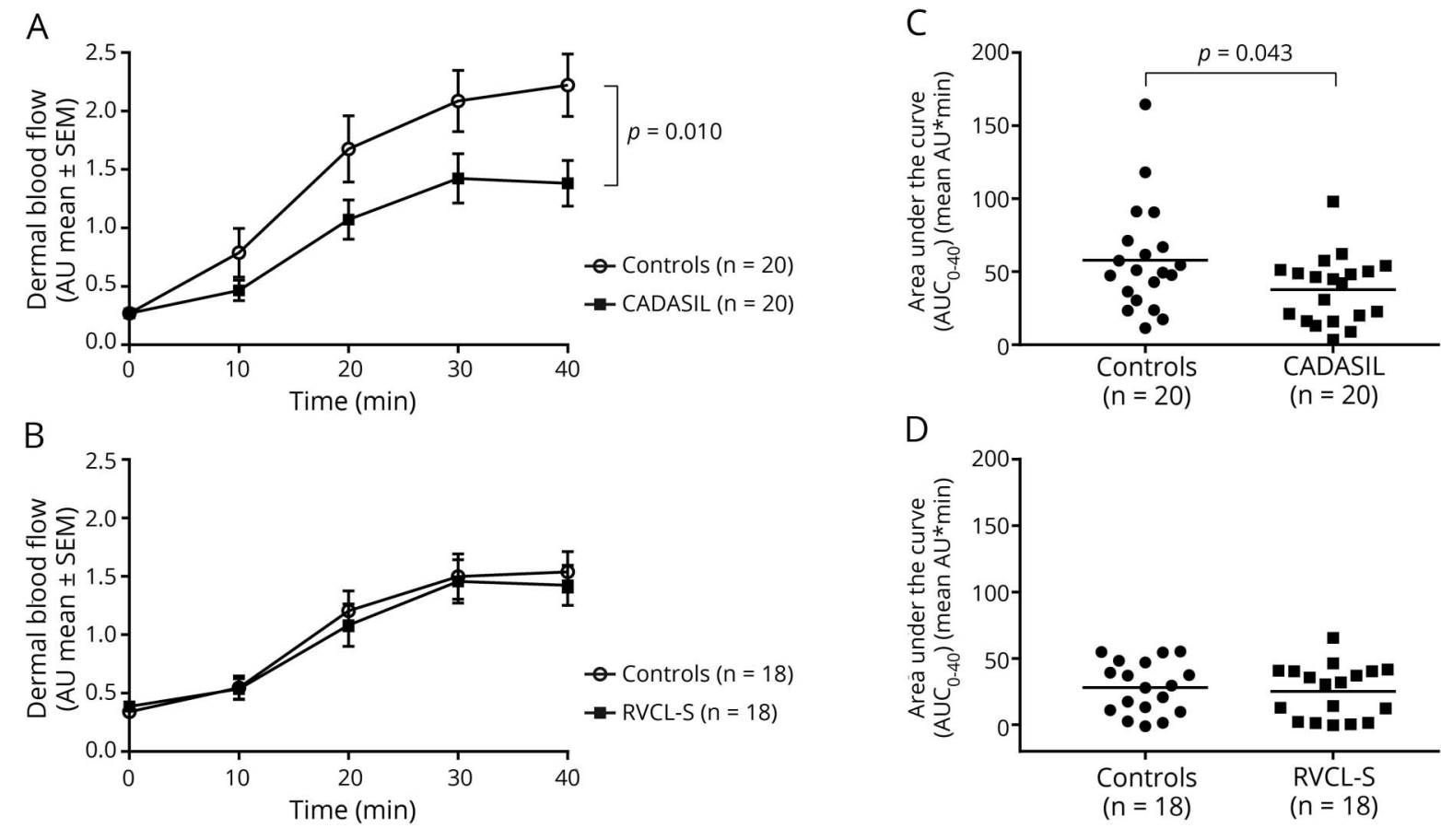

Results shown as mean \pm SEM. DBF increase over 40 minutes after capsaicin application in participants with CADASIL (A) and participants with RVCL-S (B). Total DBF response over a period of 40 minutes after capsaicin application, displayed as $A \cup C_{0-40}$, in participants with CADASIL (C) and participants with RVCL-S (D). The measurements in panels $A$ and $C$ were conducted using 2 different scanners. AU = arbitrary unit; $A U C=$ area under the curve; CADASIL $=$ cerebral autosomal dominant arteriopathy with subcortical infarcts and leukoencephalopathy; DBF = dermal blood flow; RVCL-S = retinal vasculopathy with cerebral leukoencephalopathy and systemic manifestations.

observed in participants with CADASIL. Since capsaicin activates presynaptic TRPV1 receptors on $\mathrm{A} \delta$ - and C-fiber nociceptors and leads to relaxation of VSMCs of the skin microvasculature upon CGRP release, a decreased DBF could result from defects at different levels in this pathway: (1) less sensitivity of TRPV1 receptors to capsaicin; (2) impairment of CGRP release from nociceptors; (3) a decreased expression of functional TRPV1/CGRP receptors; or (4) a decreased relaxation of VSMCs in response to an endothelium-independent stimulus. Further studies are required to elucidate the mechanism behind the decreased DBF response observed in participants with CADASIL. Given the morphologic abnormalities seen in the microvasculature of patients with CADASIL, degeneration of VSMCs, and a morphologically normal endothelium, ${ }^{5}$ a decreased relaxation of VSMCs in response to an endothelium-independent stimulus seems most plausible. Thus, our results suggest impaired endothelium-independent VSMC relaxation in CADASIL and are in line with the following results of previous studies: (1) impaired microvascular reactivity using other techniques without the involvement of CGRP $^{13-16}$; (2) reduced baseline cerebral blood flow; and (3) impaired hemodynamic reserve measured as vasodilation response to acetazolamide. ${ }^{9-11}$

By measuring FMD at the brachial artery, we did not find evidence for endothelial dysfunction in CADASIL or differences in endothelium-independent relaxation of the brachial artery after NTG administration. As such, we found no evidence of altered vascular function of conduit vessels, in this case the brachial artery in participants with CADASIL. This confirms earlier findings and is consistent with the belief that small arteries are most affected. ${ }^{13,14}$ However, in contrast to our findings, one study suggested endothelial dysfunction based on L-arginine-induced vasoreactivity of the middle cerebral artery in CADASIL. ${ }^{15}$ There is, however, a methodologic concern as that study may be biased by baseline differences between CADASIL and controls. Finally, in the microcirculation, forearm resistance arteries, impaired endothelium-dependent vasodilatation was reported. ${ }^{14}$ Therefore, although we find no evidence for endothelial dysfunction in conduit arteries, our study is limited by not investigating endothelial function in the microvasculature, as there is evidence for dysfunction of endothelium in the microcirculation of patients with CADASIL. ${ }^{14}$

The strengths of our study include the following: (1) assessment of vascular reactivity with complementary measurements of endothelial and smooth muscle cell function; (2) investigation of a unique sample of the small vessel disorders RVCL-S and CADASIL that can be considered monogenic models for vascular cerebral disorders in general; (3) use of well-validated techniques ${ }^{20,22}$; and (4) performance of the investigations by one person who was blinded to the health status of the study participants. There are also limitations to our study. Because CADASIL and RVCL-S are rare diseases, 
sample sizes are relatively small. As a consequence, we chose to focus on demonstrating a difference in response to capsaicin or NTG. Now that a difference in capsaicin-induced DBF has been demonstrated in CADASIL, it may be interesting to investigate whether there are differences in the dose-response relationship between patients with CADASIL and controls. In addition, not all measurements could be performed in all participants, but there were no differences between included and excluded participants. Furthermore, because of the different scanners used in the DBF measurements, we used different control groups for the DBF measurements. We did, however, correct for the effect of the 2 scanners used. Whereas the effect of hematocrit was corrected via peak shear stress, this was not done for hemoglobin. Hemoglobin absorbs nitric oxide; a lower hemoglobin results in an increased FMD. ${ }^{28}$ However, participants with RVCL-S display slightly lower hemoglobin and thus correction would lead to an even lower FMD in RVCL-S. The slightly (not significant) reduced FMD observed in CADASIL might be the result of the mismatch in cigarette pack-years, although only 2 heavy smokers dramatically influenced the number of pack-years. For clinical reasons, not all participants were permitted to stop their medication.

The increased prevalence of migraine in both CADASIL and RVCL-S might be related to the altered vascular properties found in the present and previous studies. Vascular dysfunction, such as endothelial dysfunction ${ }^{20}$ and increased risk of ischemic brain lesions, has been linked with migraine, making this hypothesis more amendable. ${ }^{29-31}$ In CADASIL, altered vasoreactivity of the microcirculation may induce ischemia, which may trigger cortical spreading depression, the underlying mechanism of the migraine aura. ${ }^{32}$ In line with this hypothesis, transgenic CADASIL Notch 3 mice show a decreased threshold for cortical spreading depression. ${ }^{33}$ In contrast to CADASIL, patients with RVCL-S seem to have mainly migraine without aura. An increased susceptibility for endothelial dysfunction supposedly contributes to the development of migraine without aura in RVCL-S. No migraine attacks were induced by NTG administration, possibly because of the lower-dose NTG used or sublingual administration. ${ }^{34}$

Future studies need to confirm our findings of endothelial dysfunction in RVCL-S and investigate endothelial dysfunction in microvasculature to further unravel pathophysiologic mechanisms behind the distinct vascular impairment in RVCL-S and CADASIL and determine whether our findings can be translated to the cerebral circulation. In addition, further studies may link these vascular functional markers to disease progression and to the individual symptoms of these syndromes, such as stroke, dementia, and migraine.

\section{Author contributions}

I. de Boer: writing and revising the manuscript, statistical analysis, interpretation of the data. A.H. Stam: revising the manuscript, including medical writing, study design, interpretation of data, study coordination. L. Buntinx: revising the manuscript. R. Zielman: acquisition, revising the manuscript. I. van der Steen: acquisition of data, interpretation of data. A.M.J.M. van den Maagdenberg: revising the manuscript, interpretation of data. E.J.P. de Koning: study design, revising the manuscript. M.D. Ferrari: revising the manuscript for content, interpretation of data. J.N. de Hoon: study design, revising the manuscript, interpretation of data. G.M. Terwindt: study design and supervision, revising the manuscript for content, interpretation of data.

\section{Acknowledgment}

The authors thank S. Vermeersch (Centre for Clinical Pharmacology, University Hospitals Leuven and Department of Pharmaceutical and Pharmacological Sciences, KU Leuven, Belgium), S.R. Steenmeijer, and B.S. Gagaouzova (Department of Neurology, Leiden University Medical Center, Leiden, the Netherlands) for their assistance with data acquisition.

\section{Study funding}

This work was supported by grants of the Netherlands Organisation for Scientific Research (NWO) (Vidi 917-11-319, G.M.T.) and EUROHEADPAIN (6026337; M.D.F., A.M.J.M.v.d.M., and G.M.T.).

\section{Disclosure}

The authors report no disclosures relevant to the manuscript. Go to Neurology.org/N for full disclosures.

Received November 10, 2017. Accepted in final form May 31, 2018.

\section{References}

1. Stam $\mathrm{AH}$, Kothari $\mathrm{PH}$, Shaikh A, et al. Retinal vasculopathy with cerebral leukoencephalopathy and systemic manifestations. Brain 2016;139:2909-2922.

2. Grand MG, Kaine J, Fulling K, et al. Cerebroretinal vasculopathy: a new hereditary syndrome. Ophthalmology 1988;95:649-659.

3. Jen J, Cohen $A H$, Yue $\mathrm{Q}$, et al. Hereditary endotheliopathy with retinopathy, nephropathy, and stroke (HERNS). Neurology 1997;49:1322-1330.

4. Terwindt GM, Haan J, Ophoff RA, et al. Clinical and genetic analysis of a large Dutch family with autosomal dominant vascular retinopathy, migraine and Raynaud's phenomenon. Brain 1998;121:303-316.

5. Chabriat H, Joutel A, Dichgans M, Tournier-Lasserve E, Bousser MG. CADASIL. Lancet Neurol 2009;8:643-653.

6. Joutel A, Corpechot C, Ducros A, et al. Notch3 mutations in CADASIL, a hereditary adult-onset condition causing stroke and dementia. Nature 1996;383:707-710.

7. Richards A, van den Maagdenberg AM, Jen JC, et al. C-terminal truncations in human $3^{\prime}-5$ ' DNA exonuclease TREX1 cause autosomal dominant retinal vasculopathy with cerebral leukodystrophy. Nat Genet 2007;39:1068-1070.

8. Davis GE, Norden PR, Bowers WL. Molecular control of capillary morphogenesis and maturation by recognition and remodeling of the extracellular matrix: functional roles of endothelial cells and pericytes in health and disease. Connect Tissue Res 2015;56: 392-402.

9. Chabriat H, Pappata S, Ostergaard L, et al. Cerebral hemodynamics in CADASIL before and after acetazolamide challenge assessed with MRI bolus tracking. Stroke 2000;31:1904-1912.

10. Lacombe P, Oligo C, Domenga V, Tournier-Lasserve E, Joutel A. Impaired cerebral vasoreactivity in a transgenic mouse model of cerebral autosomal dominant arteriopathy with subcortical infarcts and leukoencephalopathy arteriopathy. Stroke 2005; 36:1053-1058.

11. Liem MK, Lesnik Oberstein SA, Haan J, et al. Cerebrovascular reactivity is a main determinant of white matter hyperintensity progression in CADASIL. AJNR Am J Neuroradiol 2009;30:1244-1247.

12. Pfefferkorn T, von Stuckrad-Barre S, Herzog J, Gasser T, Hamann GF, Dichgans M. Reduced cerebrovascular $\mathrm{CO}(2)$ reactivity in CADASIL: a transcranial Doppler sonography study. Stroke 2009;32:17-21.

13. Gobron C, Vahedi K, Vicaut E, et al. Characteristic features of in vivo skin microvascular reactivity in CADASIL. J Cereb Blood Flow Metab 2007;27:250-257.

14. Stenborg A, Kalimo H, Viitanen M, Terent A, Lind L. Impaired endothelial function of forearm resistance arteries in CADASIL patients. Stroke 2007;38:2692-2697.

15. Peters N, Freilinger T, Opherk C, Pfefferkorn T, Dichgans M. Enhanced L-arginineinduced vasoreactivity suggests endothelial dysfunction in CADASIL. J Neurol 2008 $255: 1203-1208$ 
16. Campolo J, De Maria R, Frontali M, et al. Impaired vasoreactivity in mildly disabled CADASIL patients. J Neurol Neurosurg Psychiatry 2012;83:268-274.

17. Headache Classification Committee of the International Headache Society. The International Classification of Headache Disorders, 3rd edition (beta version). Cephalalgia 2013;33:629-808.

18. Miller D, Waters DD, Warnica W, Szlachcic J, Kreeft J, Théroux P. Is variant angina the coronary manifestation of a generalized vasospastic disorder? N Engl J Med 1981;304: 763-766.

19. Corretti MC, Anderson TJ, Benjamin EJ, et al. Guidelines for the ultrasound assessment of endothelial-dependent flow-mediated vasodilation of the brachial artery: a report of the International Brachial Artery Reactivity Task Force. J Am Coll Cardiol 2002;39:257-265.

20. Vanmolkot FH, Van Bortel LM, de Hoon JN. Altered arterial function in migraine of recent onset. Neurology 2007;68:1563-1570.

21. Van der Schueren BJ, Rogiers A, Vanmolkot FH, et al. Calcitonin gene-related peptide $_{8-37}$ antagonizes capsaicin-induced vasodilation in the skin: evaluation of a human in vivo pharmacodynamic model. J Pharmacol Exp Ther 2008;325:248-255.

22. Van der Schueren BJ, de Hoon JN, Vanmolkot FH, et al. Reproducibility of the capsaicin-induced dermal blood flow response as assessed by laser Doppler perfusion imaging. Br J Clin Pharmacol 2007;64:580-590.

23. Volkman HE, Stetson DB. The enemy within: endogenous retroelements and autoimmune disease. Nat Immunol 2014;15:415-422.

24. Stevenson SF, Doubal FN, Shuler K, Wardlaw JM. A systematic review of dynamic cerebral and peripheral endothelial function in lacunar stroke versus controls. Stroke 2010;41:434-442.

25. Herrick AL. Pathogenesis of Raynaud's phenomenon. Rheumatology 2005;44:587-596.
26. Heringa SM, van den Berg E, Reijmer YD, et al. Markers of low-grade inflammation and endothelial dysfunction are related to reduced information processing speed and executive functioning in an older population: the Hoorn Study. Psychoneuroendocrinology 2014;40:108-118.

27. Joutel A, Andreux F, Gaulis S, et al. The ectodomain of the Notch3 receptor accumulates within the cerebrovasculature of CADASIL patients. J Clin Invest 2000;105: 597-605.

28. Meyer C, Heiss C, Drexhage C, et al. Hemodialysis-induced release of hemoglobin limits nitric oxide bioavailability and impairs vascular function. J Am Coll Cardiol 2010;55:454-459.

29. Kruit MC, van Buchem MA, Hofman PA, et al. Migraine as a risk factor for subclinical brain lesions. JAMA 2004;291:427-434.

30. Kurth T, Chabriat H, Bousser MG. Migraine and stroke: a complex association with clinical implications. Lancet Neurol 2012;11:92-100.

31. Palm-Meinders IH, Koppen H, Terwindt GM, et al. Structural brain changes in migraine. JAMA 2012;308:1889-1897.

32. Lauritzen M. Pathophysiology of the migraine aura: the spreading depression theory. Brain 1994;117:199-210.

33. Eikermann-Haerter K, Yuzawa I, Dilekoz E, Joutel A, Moskowitz MA, Ayata C. Cerebral autosomal dominant arteriopathy with subcortical infarcts and leukoencephalopathy syndrome mutations increase susceptibility to spreading depression. Ann Neurol 2011;69:413-418.

34. Sances G, Tassorelli C, Pucci E, Ghiotto N, Sandrini G, Nappi G. Reliability of the nitroglycerin provocative test in the diagnosis of neurovascular headaches. Cephalalgia 2004;24:110-119. 


\section{Neurology}

\section{RVCL-S and CADASIL display distinct impaired vascular function \\ Irene de Boer, Anine H. Stam, Linde Buntinx, et al. \\ Neurology 2018;91;e956-e963 Published Online before print August 3, 2018 \\ DOI 10.1212/WNL.0000000000006119}

\section{This information is current as of August 3, 2018}

\section{Updated Information \& Services}

\section{References}

Subspecialty Collections

Permissions \& Licensing

\section{Reprints}

including high resolution figures, can be found at: http://n.neurology.org/content/91/10/e956.full

This article cites 34 articles, 10 of which you can access for free at: http://n.neurology.org/content/91/10/e956.full\#ref-list-1

This article, along with others on similar topics, appears in the following collection(s):

All Cerebrovascular disease/Stroke

http://n.neurology.org/cgi/collection/all_cerebrovascular_disease_strok e

All Genetics

http://n.neurology.org/cgi/collection/all_genetics

CADASIL

http://n.neurology.org/cgi/collection/cadasil

Vascular dementia

http://n.neurology.org/cgi/collection/vascular_dementia

Information about reproducing this article in parts (figures,tables) or in its entirety can be found online at:

http://www.neurology.org/about/about_the_journal\#permissions

Information about ordering reprints can be found online:

http://n.neurology.org/subscribers/advertise

Neurology $®$ is the official journal of the American Academy of Neurology. Published continuously since 1951, it is now a weekly with 48 issues per year. Copyright (C) 2018 American Academy of Neurology. All rights reserved. Print ISSN: 0028-3878. Online ISSN: 1526-632X.

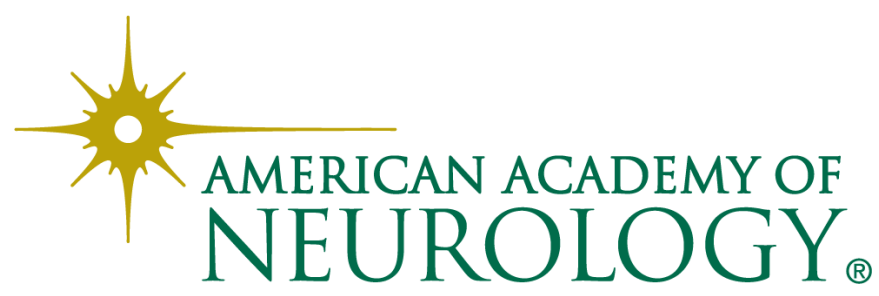

